Research Article

\title{
Incidence of infections with extended spectrum beta Lactamase (ESBL)-producing gram-negative bacteria among patients admitted in medical intensive care unit of tertiary care hospital
}

\author{
Perumal P.G. ${ }^{1}$, Jnaneshwara K.B. ${ }^{2}$, Patil A.B. ${ }^{3}$, Akshay $\mathbf{R}^{4}$ \\ ${ }^{1}$ Dr. Ganesh Perumal P, Post Graduate, ${ }^{2}$ Dr. Jnaneshwara KB, Assistant Professor, ${ }^{3}$ Dr. Asha B. Patil, Professor and \\ Head, ${ }^{4}$ Dr. Akshay R. Junior Resident; all authors are affiliated with KIMS, Hubballi, RGUHS, Karnataka, India.
}

Address for Correspondence: Dr. Ganesh Perumal P, Email: drganeshp2014@gmail.com

\begin{abstract}
Introduction: Extended spectrum beta-lactamases (ESBLs) are beta-lactamases capable of conferring bacterial resistance to the Penicillins, first, second and third generation cephalosporins, and Aztreonam (but not the Cephamycins or Carbapenems). Clinicians, Microbiologists and hospital epidemiologists are concerned about ESBL-producing Gram negative bacteria because of increased incidence of such infections, limitations of effective antimicrobial therapy and adverse patient outcomes. Aims and Objectives: To find the incidence of infections caused by ESBL producing Gram negative bacteria among patients admitted in Medical ICU of tertiary care hospital. To compare the antimicrobial susceptibility patterns of the ESBL producing Gram negative isolates with ESBL non-producing isolates. Materials and Methods: Clinical samples were collected from patients admitted in Medical ICU \& processed as per standard protocol. Antibiotic susceptibility was performed by Kirby-Bauer disc diffusion method. Screening for ESBL production was done as per CLSI guidelines. Presence of ESBL was detected by Phenotypic confirmatory disc diffusion method using discs containing $30 \mu \mathrm{g}$ of Ceftazidime with and without $10 \mu \mathrm{g}$ of Clavulanic acid on Mueller-Hinton Agar. Results: A total of 50 samples were collected. Of these, majority (38\%) of samples were urine followed by sputum (36\%). Of the 50 samples, majority of the isolates were Klebsiella spp and E.coli, 14(28\%) each. Among 50 samples, 42(84\%) isolates were ESBL producers. Of the 42 ESBL producing organisms, majority(13(30.9\%)) of them were Klebsiella spp. Conclusion: In the present study, we found an alarming number (84\%) of ESBL producing Gram negative isolates in Medical ICU patients. Strict antibiotic policies and measures to limit indiscriminate use of Cephalosporins should be undertaken to minimize the emergence of such resistance.
\end{abstract}

Key words: ESBL, Gram negative bacteria, Medical ICU.

\section{Introduction}

Extended spectrum beta-lactamases (ESBLs) are betalactamases capable of conferring bacterial resistance to the Penicillins, first, second and third generation cephalosporins, and Aztreonam (but not the Cephamycins or Carbapenems) [1]. Typically, they derive from genes TEM-1, TEM-2, or SHV-1 by mutations that alter the amino acid configuration around the active site of these beta-lactamases. This extends the spectrum of beta-lactam antibiotics susceptible to hydrolysis by these enzymes [2]. ESBL are most commonly produced by Klebsiella spp and E.coli.

Manuscript received: $28^{\text {th }}$ April 2017

Reviewed: $8^{\text {th }}$ May 2017

Author Corrected: $17^{\text {th }}$ May 2017

Accepted for Publication: 24 $4^{\text {th }}$ May 2017
However, Enterobacter, Salmonella, Proteus, Citrobacter, Morganella,Serratia,Shigella, Pseudomonas and Burkholderia spp also produce them [3]. Clinicians, Microbiologists and hospital epidemiologists are concerned about ESBL-producing Gram negative bacteria because of increased incidence of such infections, limitations of effective antimicrobial therapy and adverse patient outcomes.

Special efforts should be undertaken by Clinical microbiology laboratories as recommended by the Clinical and Laboratory Standards Institute (CLSI) for ESBL detection [4,5]. ESBL detection is not commonly carried out in laboratories in developing countries due 
Research Article

to lack of awareness and facilities to conduct ESBL identification [6]. Detection of ESBL producing organism from samples is important because this represents an epidemiologic marker of colonization and therefore there is potential for transfer of such organisms to other patients [7]. Within countries, hospital-to-hospital variability in ESBLs may also be marked [8].

This prospective Cross-sectional study is conducted to find and compare incidence of infections with ESBL producing Gram negative bacteria among patients admitted in Medical intensive care unit of Karnataka Institute of Medical Sciences, Hubballi. Besides it is important to understand the extent of spread of these isolates in the community so as to formulate corrective measures.

\section{Aims and Objectives}

To find the incidence of infections caused by ESBL producing Gram negative bacteria among patients admitted in Medical ICU of tertiary care hospital. To compare the antimicrobial susceptibility patterns of the ESBL producing Gram negative isolates with ESBL non-producing isolates.

\section{Materials and Methods}

- The study has been carried out after obtaining the clearance of Institutional ethical committee.

- Study design: Prospective Cross-sectional study

- Study site: Medical Intensive care unit of KIMS Hospital, Hubballi.

- Duration of study: June $1^{\text {st }}$ to July $31^{\text {st }}, 2014$.

- Sample size: 50

\section{Inclusion criteria}

$>$ Patients admitted in Medical ICU during study period were included.

$>$ Only Gram negative isolates were included.

\section{Exclusion criteria}

$>$ Isolates other than Gram negative bacteria

$>$ Repeat isolates from same patient.

Sample collection and processing: Clinical samples were collected from patients admitted in Medical ICU $\&$ processed as per standard protocol.

\section{Methodology}

Antibiotic susceptibility was performed by Kirby-Bauer disc diffusion method. Screening for ESBL production was done as per CLSI guidelines [9]. Presence of ESBL was detected by Phenotypic confirmatory disc diffusion method using discs containing $30 \mu \mathrm{g}$ of Ceftazidime with and without $10 \mu \mathrm{g}$ of Clavulanic acid on Mueller-Hinton Agar. ESBL production was inferred if the inhibition zone increases by $5 \mathrm{~mm}$ towards Ceftazidime plus clavulanic acid in comparison to Ceftazidime disc alone [9].

Statistical Analysis was done by Chi-square test using SPSS software.

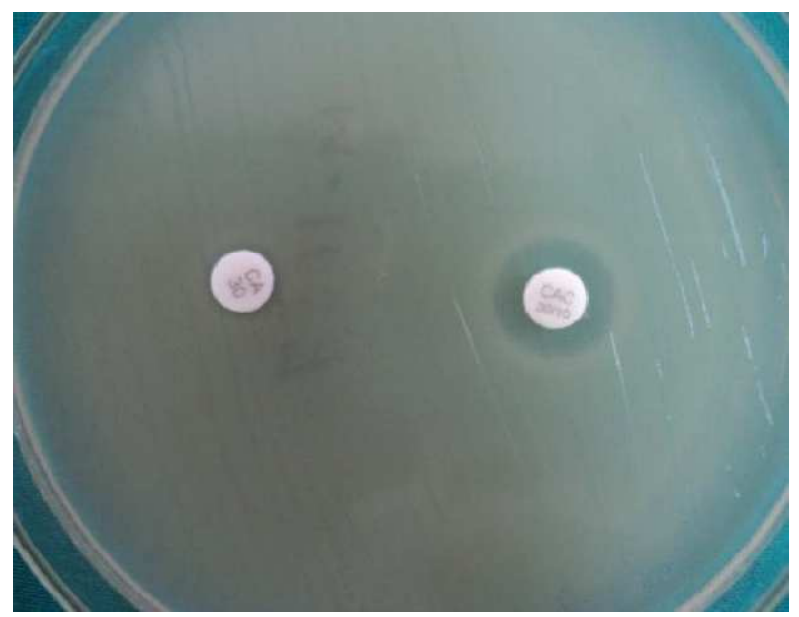

Fig 1: Phenotypic confirmatory test showing ESBL positive isolate

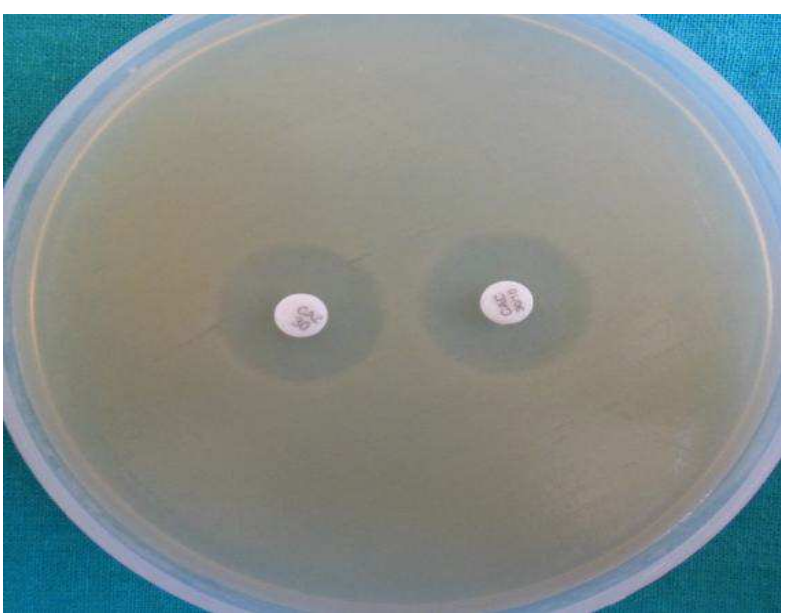

Fig 2: Phenotypic confirmatory test showing ESBL negative isolate 


\section{Observations and Results}

The present study was carried out in the Department of Microbiology, Karnataka Institute of Medical Sciences (KIMS), Hubballi.

Table-1: Specimen-wise distribution of isolates.

\begin{tabular}{|c|c|c|}
\hline Specimen & Number (n=50) & Percentage \\
\hline Ascitic fluid & 3 & $8 \%$ \\
\hline CSF & 4 & $2 \%$ \\
\hline ET tube secretion & 1 & $8 \%$ \\
\hline Pleural fluid & 4 & $2 \%$ \\
\hline Pus & 1 & $36 \%$ \\
\hline Sputum & 18 & $38 \%$ \\
\hline Urine & 19 & $\mathbf{1 0 0} \%$ \\
\hline Total & $\mathbf{5 0}$ & $8 \%$ \\
\hline
\end{tabular}

Majority (38\%) of samples were urine followed by sputum (36\%).

Table-2: Distribution of isolates.

\begin{tabular}{|c|c|c|}
\hline Isolate & Number & Percentage(\%) \\
\hline E.coli & 14 & $28 \%$ \\
\hline Klebsiella spp. & 14 & $18 \%$ \\
\hline Pseudomonas spp & 9 & $14 \%$ \\
\hline Citrobacter spp. & 7 & $10 \%$ \\
\hline NFGNB & 5 & $2 \%$ \\
\hline Providencia spp. & 1 & $28 \%$ \\
\hline
\end{tabular}

Of the 50 samples, majority of isolates were Klebsiella spp and E.coli,14(28\%) each.

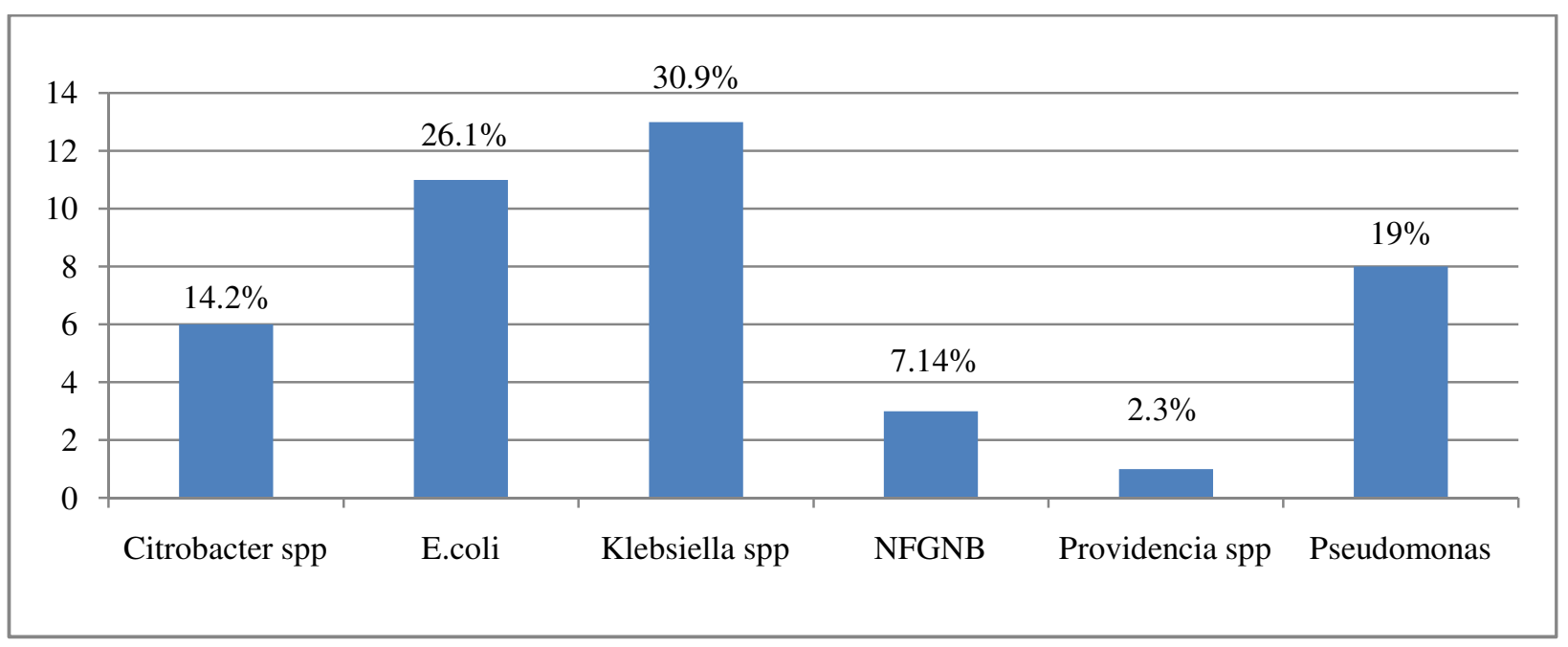

Graph-1: Distribution of isolates with ESBL

Of the 42 ESBL producing organisms, majority of them were Klebsiella spp which was 13 (30.9\%). 
Research Article

Table-3: Comparison of antibiotic resistance pattern of ESBL positive and ESBL negative isolates.

\begin{tabular}{|c|c|c|c|c|c|c|}
\hline \multirow[t]{2}{*}{ Antibiotics } & \multicolumn{2}{|c|}{ ESBL positive $n=42$} & \multicolumn{2}{|c|}{ ESBL negative $n=8$} & \multirow[t]{2}{*}{ p value } & \multirow[t]{2}{*}{ Significance } \\
\hline & Resistant & $\%$ & Resistant & $\%$ & & \\
\hline Amikacin & 11 & 26.19 & 1 & 12.5 & 0.017 & $\mathrm{~S}$ \\
\hline Netilmicin & 13 & 30.95 & 0 & 0 & 0.567 & NS \\
\hline Amoxy-clavulanic acid & 24 & 57.14 & 1 & 12.5 & 0.009 & $S$ \\
\hline Ceftazidime & 5 & 11.90 & 1 & 12.5 & 0.738 & NS \\
\hline Cefepime & 28 & 66.66 & 2 & 25 & 0.042 & S \\
\hline Cefaperazone & 6 & 14.28 & 1 & 12.5 & 0.896 & NS \\
\hline Cefotaxime & 27 & 64.28 & 2 & 25 & 0.002 & $S$ \\
\hline Cefoxitin & 21 & 50 & 4 & 50 & 0.882 & NS \\
\hline Ciprofloxacin & 3 & 7.14 & 0 & 0 & 0.436 & NS \\
\hline Levofloxacin & 8 & 19.04 & 0 & 0 & 0.191 & NS \\
\hline Norfloxacin & 11 & 26.19 & 0 & 0 & 0.188 & NS \\
\hline Ofloxacin & 7 & 16.66 & 1 & 12.5 & 0.402 & NS \\
\hline Pefloxacin & 18 & 42.85 & 1 & 12.5 & 0.179 & NS \\
\hline Imipenem & 6 & 14.28 & 0 & 0 & 0.007 & $S$ \\
\hline Pip-tazobactam & 10 & 23.8 & 2 & 25 & 0.029 & $\mathrm{~S}$ \\
\hline Tetracycline & 25 & 59.52 & 2 & 25 & 0.058 & NS \\
\hline
\end{tabular}

Difference was statistically significant for Amikacin, Amoxy-clavulanic acid, Cefepime, Cefotaxime, Imipenem and Piperacillin+tazobactam. ESBL producing isolates were found to show higher rates of resistance when compared to non ESBL producers.

\section{Discussion}

A total of fifty isolates from various clinical samples from medical ICU were screened for ESBL Production. Screening for ESBL production is done as per CLSI guidelines. Of these 50 isolates, 42(84\%) were ESBL producers. Of these, majority of the isolates were from urine and sputum, 16(38\%) each.

In India, ESBL presence rate varies in different situations from 24 to $84 \%$ [10]. A study from Coimbatore, Tamil Nadu, presence of ESBLs to be $40 \%$, while a study done from Nagpur showed it as $50 \%$ [11,12]. Another study in 2005, from New Delhi, showed $68.78 \%$ of the strains of Gram negative bacteria to be ESBL producers [13]. In our study, presence rate of ESBL was found to be $84 \%$. This must be due to injudicious usage of Cephalosporins in Medical ICU patients.

Klebsiella and E.coli were the predominant ESBL producers ( $28 \%$ each) lower than the study done by
Neelam Taneja et al who observed 51.2\% Klebsiella spp followed by $40.2 \%$ Escherichia coli [14].

The incidence of ESBL was found to be $84 \%$ higher than in the study done by Kumar D, Singh AK, Ali MR, Chander $\mathrm{Y}$ to determine the antimicrobial sensitivity profile of ESBL producing E. coli isolates from various clinical samples such as pus, urine, blood, cerebrospinal fluid (CSF), stool, sputum, swabs, and different body fluids which was $55.5 \%$ [15].

ESBL producing isolates were found to show higher rate of resistance to Cefipime $(66.6 \%)$, Cefotaxime $(64.28 \%)$ and Amoxy-clavulanic acid (57.14\%). Imipenem (14.28\%), Piperacillin-Tazobactam (23.8\%), and Ciprofloxacin (7.14\%) were found to be the effective antibiotic in ESBL producing isolates. It is statistically significant for Amikacin, Amoxyclavulanic acid, Cefepime, Cefotaxime, Imipenem and Piperacillin+tazobactam antibiotics. 
Research Article

Detection of ESBL production is of paramount importance in hospital settings as these strains are probably more prevalent than currently recognized; these enzymes constitute a serious threat to currently available antibiotics. Institutional outbreaks are increasing because of selective pressure due to indiscriminate use of expanded- spectrum Cephalosporins and lapses in effective control measures [16].

Screening of ESBL in Gram negative bacteria poses considerable therapeutic challenges in critical care patients. The infections which are caused by ESBL producing Gram negative bacteria have been reported with an increasing frequency in the intensive care units and they are associated with a significant morbidity and mortality [17].

One of the areas of interest in infections in ICU is in the trend in the antibiotic susceptibility patterns (AST) of common pathogens in ICU. This is important as antibiotic guidelines are commonly made based on them and changes in the AST patterns need $o$ be reflected in regularly updated antibiotic guidelines [18]. Strategies to keep a check on the emergence of such drug resistant microbes by hospital environmental surveillance and laboratory monitoring should form an important aspect of Hospital Infection Control policy guidelines [3].

\section{Conclusion}

In the present study, we found an alarming number of ESBL producing Gram negative isolates. The laboratories should have the capacity to detect ESBL producers, so that appropriate therapy can be chosen for patient management. The report must also include a note that ESBL producer may result in therapeutic failure with antimicrobials such as Penicillin, Aztreonam and Cephalosporin.

Considering the gravity of the implication of wrong therapy in critical care, looking for ESBL producers must be made mandatory in all reporting in Microbiology laboratories and clinicians also educated on the issue. Strict antibiotic policies and measures to limit indiscriminate use of Cephalosporins should be undertaken to minimize the emergence of such resistance.

Funding: Nil, Conflict of interest: None initiated, Permission from IRB: Yes

\section{References}

1. Idowu OJ, Onipede AO, Orimolade AE, Akinyoola LA, Babalola GO. Extended-spectrum beta-lactamase orthopedic wound infections in Nigeria. J Global Infect Dis $2011 ; 3: 211-5$.

2. Paterson DL, Bonomo RA. Extended-spectrum betalactamases: a clinical update. Clin Microbiol Rev. 2005 Oct;18(4):657-86.

3. Grover CN, Sahni AK, Bhattacharya CS. Therapeutic challenges of ESBL and AmpC beta-lactamase producers in a tertiary care center. Indian medical journal of armed forces 2013;69(1):4-10.

4. Paterson DL, Bonomo RA. Extended-spectrum betalactamases: a clinical update. Clin Microbiol Rev. 2005 Oct;18(4):657-86.

5. Nathisuwan S, Burgess DS, Lewis JS 2nd. Extendedspectrum beta-lactamases: epidemiology, detection, and treatment. Pharmacotherapy. 2001 Aug;21(8):920-8.

6. Tsering DC, Das S, Adhiakari L, Pal R, Singh TS. Extended Spectrum Beta-lactamase Detection in Gramnegative Bacilli of Nosocomial Origin. J Glob Infect Dis. 2009 Jul;1(2):87-92. doi: 10.4103/0974-777X. 56247.

7. Rupp ME, Fey PD. Extended spectrum betalactamase (ESBL)-producing Enterobacteriaceae: considerations for diagnosis, prevention and drug treatment. Drugs. 2003;63(4):353-65.

8. Babini GS, Livermore DM. Antimicrobial resistance amongst Klebsiella spp. collected from intensive care units in Southern and Western Europe in 1997-1998. J Antimicrob Chemother 2000; 45:183-9.[PUBMED]

9. Clinical and Laboratory Standards Institute. Performance standards for antimicrobial susceptibility testing; $18^{\text {th }}$ informational supplement 2012.

10. Das A, Ray P, Garg R, Kaur B. Extended spectrum beta-lactamase production in Gram negative bacterial isolates from cases of septicemia. Proceedings of the Silver Jubilee Conference of IAMM. New Delhi: All India institute Of medical Sciences; 2001.

11. Babypadmini S, Appalaraju B. Extended spectrum lactamases in urinary isolates of Escherichia coli and 
Klebsiella pneumoniae - prevalence and susceptibility pattern in a tertiary care hospital. Indian $\mathrm{J}$ Med Microbiol. 2004 Jul-Sep;22(3):172-4.

12. Tankhiwale SS, Jalgaonkar SV, Ahamad S, Hassani U. Evaluation of extended spectrum beta lactamase in urinary isolates. Indian J Med Res. 2004 Dec;120 (6): 553-6.

13. Mohanty S, Singhal R, Sood S, Dhawan B, Das BK, Kapil A. Comparative in vitro activity of betalactam/beta-lactamase inhibitor combinations against gram negative bacteria. Indian J Med Res. 2005 Nov; 122(5):425-8.

14. Taneja N, Rao P, Arora J, Dogra A. Occurrence of ESBL \& Amp-C beta-lactamases \& susceptibility to newer antimicrobial agents in complicated UTI. Indian J Med Res. 2008 Jan;127(1):85-8.

15. Shashwati N, Kiran T, Dhanvijay AG. Study of Extended spectrum $\beta$ - lactamase producing Enterobacteriaceae and antibiotic co-resistance in a tertiary care teaching hospital. J Nat Sci Biol Med. 2014; 5(1): 30-5.

16. Bajpai T, Pandey M, Varma M, Bhatambare GS. Prevalence of extended spectrum beta-lactamase producing uropathogens and their antibiotic resistance profile in patients visiting a tertiary care hospital in central India: Implications on empiric therapy. Indian J Pathol Microbiol. 2014 Jul-Sep;57(3):407-12. doi: 10. 4103/0377-4929.138733.

17. Itokazu GS, Quinn JP, Bell-Dixon C, Kahan FM, Weinstein RA. Antimicrobial resistance rates among aerobic gram-negative bacilli recovered from patients in intensive care units: evaluation of a national postmarketing surveillance program. Clin Infect Dis. 1996 Oct;23(4):779-84.

18. Kaul S, Brahmadathan KN, Jagannati M. one year trends in the Gram negative bacterial antibiotic susceptibility patterns in a Medical ICU in South India. 2007; 25(3): 230-235.

\section{How to cite this article?}

Perumal P.G, Jnaneshwara K.B, Patil A.B, Akshay R. Incidence of infections with extended spectrum beta Lactamase (ESBL)-producing gram-negative bacteria among patients admitted in medical intensive care unit of tertiary care hospital.Trop J Path Micro 2017;3(2):168-173.doi: 10.17511/jopm.2017.i2.17. 